\title{
Penetrating Superior Sagittal Sinus Post Part Injuries by Carpenter's Nail
}

\author{
Zabsonré Denléwendé Sylvain ${ }^{1}$, Kinda Boureima ${ }^{2}$, Diallo Ismael ${ }^{3}$, Sondo Kongnimissom Apoline ${ }^{3}$, \\ Savadogo Mamadou ${ }^{3}$, Korsaga Alexandre ${ }^{4}$, Tinto Sayouba ${ }^{4}$, Haro Yacouba $^{1}$, Kabré Abel ${ }^{1}$ \\ ${ }^{1}$ Neurosurgery Department, Yalgado Ouedraogo Teaching Hospital, Ouagadougou, Burkina Faso \\ ${ }^{2}$ Anesthésia and Reanimaton Department, Yalgado Ouedraogo Teaching Hospital, Ouagadougou, Burkina Faso \\ ${ }^{3}$ Infectiology Department, Yalgado Ouedraogo Teaching Hospital, Ouagadougou, Burkina Faso \\ ${ }^{4}$ Trauma and Orthopedic Department, Yalgado Ouedraogo Teaching Hospital, Ouagadougou, Burkina Faso
}

\section{Email address:}

szabsonre@gmail.com (Z. D. Sylvain),kindab2@yahoo.fr(K. Boureima),illah_diallo@hotmail.com (D. Ismael), sondoapoline@yahoo.fr(S.K. Appoline),savadoma@gmail.com (S. Mamadou),korsalexs@yahoo.fr(K. Alexandre), drstinto@yahoo.fr(T. Sayouba), yaksterharo@gmail.com (H. Yacouba), kabrel@yahoo.fr (K. Abel)

${ }^{*}$ Corresponding author

\section{To cite this article:}

Zabsonré Denléwendé Sylvain, Kinda Boureima, Diallo Ismael, Sondo Kongnimissom Apoline, Savadogo Mamadou, Korsaga Alexandre, Tinto Sayouba, Haro Yacouba, Kabré Abel. Penetrating Superior Sagittal Sinus Post Part Injuries by Carpenter's Nail. International Journal of Neurosurgery. Vol. 3, No. 1, 2019, pp. 1-4. doi: 10.11648/j.ijn.20190301.11

Received: March 18, 2019; Accepted: April 23, 2019; Published: June 5, 2019

\begin{abstract}
Introduction. Superior sagittal sinus posterior part injuries can rapidly lead to death by uncontrollable bleeding. The type of weapon used, the size of the sinus wound and the portion of the sinus concerned can make their gravities. We report diagnostic circumstances, treatment and evolution of 3 cases of penetrating superior sagittal sinus injuries by carpenter's nail. Methods. We describe 3 cases of a penetrating superior sagittal sinus posterior part injuries by carpenter's nail admitted in Neurosurgery department of Yalgado Ouédraogo University Teaching Hospital of Ouagadougou in 2007, 2013 and 2017. Results. Three patients aged 25, 28 and 24 years respectively admitted 19 hours on average after a traumatic brain injury by a penetrating object. Circumstance was the popular verdict 1 case. In the other cases, the circumstance could not be elucidated. The neurological examination was normal for the 3 patients. Local examination noted in 2 patients, a nail implanted in the skull in the posterior part of the median line. In 1 patient, there were 2 punctiforms wounds of the scalp in the posterior part of the median line. CT scan showed a large nail about $10 \mathrm{~cm}$ long in 2 patients and 2 nails of the same size in 1 patient. These nails were in contact or crossing the superior sagittal sinus in its posterior part. The removal of these nails was done under general anesthesia. The postoperative course was simple under antibiotic prophylaxis. Conclusion. Posterior sagittal sinus injuries by carpenter's nails were criminal origin in a context of popular justice. During their ablation under general anesthesia, bleeding from the superior sagittal sinus caused by nails removal was controlled by finger compression and stopped by placement of hemostatic compresses. Apposition of epicranium reinforced the dura closure.
\end{abstract}

Keywords: Head Injuries, Carpenter's Nail, Superior Sagittal Sinus

\section{Introduction}

Superior sagittal sinus posterior part (the $2 / 3$ posterior) injuries are most often at the origin of intracranial bleeding which is difficult to control and can quickly lead to death. They are of various causes (iatrogenic, traumatic....). Penetrating superior sagittal sinus injuries are traumatic and most often related to aggression. The type of weapon used, the size of the sinus wound and the portion of the sinus concerned can make their gravities. We report diagnostic circumstances, treatment and evolution of 3 cases of penetrating superior sagittal sinus injuries by carpenter's nail.

\section{Methodes}

We describe 3 cases of a penetrating superior sagittal sinus 
posterior part injuries by carpenter's nail admitted in Neurosurgery department of Yalgado Ouédraogo University Teaching Hospital of Ouagadougou in 2007, 2013 and 2017. The posterior part of the superior sagittal is represented by its posterior $2 / 3$; the anterior third being its anterior party.

\section{Observations}

\subsection{Observation 1}

Mr SR, 25-year-old, was admitted in January 2007 for a traumatic brain injury with a notion of brief initial loss of consciousness. No pathological antecedents had been found. A carpenter's nail about 10 centimeters long had been implanted in his skull about 27 hours before his admission. The precise circumstances of this act could not be elucidated because there were 2 versions. The parents of the patient saying that he was a mental patient and that he would have implanted this nail without their knowledge. A rumor said that the patient had been a victim of the popular verdict after being caught in a crime of theft. He had initially been managed in a peripheral health center where prophylactic antibiotics had been introduced. The neurological examination was normal. At the local examination, one end (the "head") of a nail totally fled into the skull was noted on the median line (middle third of superior sagittal sinus). The psychiatric evaluation done twice in an interval of one month was normal. The CT scan showed the "head" of the nail at the indicated seat and its "tip" in the third ventricle. There was virtually no metal artifact or significant damage to the brain parenchyma. The patient was operated on, approximately 16 hours after admission. The nail has been simply removed under general anesthesia. Bleeding of the superior sagittal sinus caused by nail removal was controlled by finger compression and stopped by placing hemostatic compresses in the hole left by the nail. Apposition of epicranium reinforced the dura closure. The postoperative course was simple. The patient was discharged from hospital for his home on the postoperative day 5. Antibiotic prophylaxis started from the peripheral health unit was continued until the patient was discharged. Figure 1 presents the clinical and CT scan aspects of lesions noted in this patient.

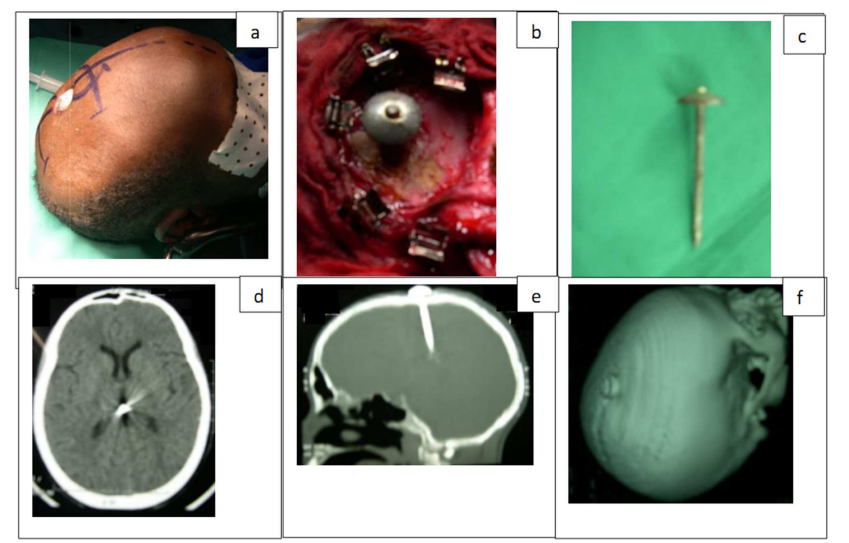

Figure 1. Lesions observed in the patient of observation 1: Appearance before (a) and during (b) operation; nail after removal (c); CT scan in axial section parenchymal window (d), in sagittal reconstruction bone window (e) and in three-dimensional reconstruction (f).

\subsection{Observation 2}

Mr. OE, 28-year-old, was admitted in December 2013 for a traumatic brain injury with a brief notion of initial loss of consciousness by a penetrating object. No pathological antecedents had been found. Two long nails of about 10 centimeters had been implanted in his skull for about 24 hours by the popular verdict after he was caught in the act of adultery in a neighboring village. He had initially been managed in a peripheral health center where prophylactic antibiotics had been introduced. The local examination noted at the level of the parietal region (middle third of superior sagittal sinus) the point of entry of two nails; one anterior on the median line and the other posterior in sagittal left. These entry points were in the form of inflammatory skin lesions. The rest of the clinical examination was normal apart from linear cutaneous excoriations disseminated on all the body (lesions of chicotte). The CT scan objectified the heads of the two nails at the level of the parietal region. The anterior nail on the middle line and the posterior nail in left sagittal para and perforated the false. There was a small metal artefact without significant parenchyma lesion. It was performed under general anesthesia, about 20 hours after admission, removal of nails. Bleeding of the superior sagittal sinus caused by this ablation was controlled by finger compression and stopped by placing hemostatic compresses in the hole left by the nails. Apposition of epicranium reinforced the dura closure. The postoperative course was simple. The patient came out of hospital for his home on the $t$ postoperative day 3. Antibiotic prophylaxis started from the peripheral health center was continued until the patient was discharged. Figure 2 illustrates the lesions noted in this patient.

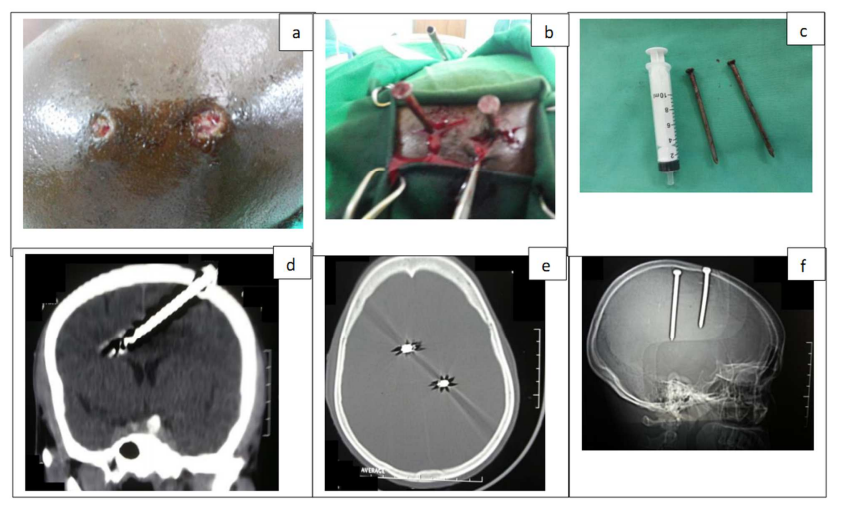

Figure 2. Lesions observed in the patient of observation 2: Appearance before (a) and during (b) operation; nails after removal (c); CT scan in coronal reconstruction parenchymal window (d), in axial section bone window (e) and in three-dimensional reconstruction (f).

\subsection{Observation 3}

Mr S.A., 24-year-old construction, worker, was admitted in December 2017 for a traumatic brain injury without a notion of initial loss of consciousness by a penetrating object. No pathological antecedents had been found. A carpenter's nail about 10 centimeters long had been implanted in his 
skull about 6 hours before admission. The exact circumstances could not be specified. The patient was found by his teammates on the construction site where they worked. At admission, he complained of severe headache. The neurological examination was normal. The local examination noted, on the midline at the level of the parietal region (middle third of superior sagittal sinus), one end (the "head") of a nail almost completely implanted into the skull. The CT scan objectified the nail on the midline most likely crossing the superior sagittal sinus in its middle third. The patient was operated on, approximately 12 hours after admission. Blood most likely from the superior sagittal sinus squirted with removal of the nail. This bleeding was controlled by finger compression and stopped by placing hemostatic compresses in the hole left by the nail. The epicranium reinforced the dura closure. Antibiotic prophylaxis started in the emergency department was continued postoperatively. The postoperative course was simple. On the third postoperative day the patient ran away from the hospital. Figure 3 the objectified lesions in this patient.

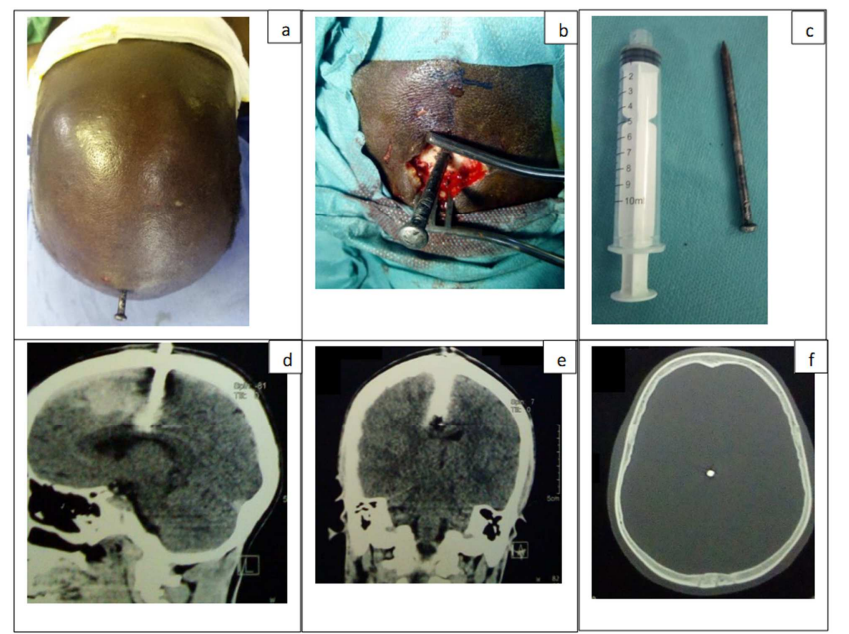

Figure 3. Lesions observed in the patient of observation 3: Appearance before (a) and during (b) operation; nail after removal (c); CT scan in sagittal reconstruction parenchymal window $(d)$; in coronal reconstruction parenchymal window (e) and axial section bone window (f).

\section{Discussion}

The precision of the act of implanting the nail, the target (posterior part of the superior sagittal sinus) and the total or almost total implanting of the nail in the skull militated in favor of a deliberate act to give death in a less "atrocious" way. It would be a popular verdict on an individual caught in a crime in society (theft, rape, adultery). Similar popular verdicts to kill a criminal more or less atrociously were known such as stoning, enema or forced ingestion of hydrochloric acid commonly known as "battery water". Fortunately, these practices have almost disappeared with greater control of law enforcement and justice. In our series the fragrant crime of adultery and the homicide attempt have been recognized by one patient and his entourage. In the other cases, since the psychiatric evaluation was almost normal for someone with a psychiatric history, we think that the patients and their entourage have expressly hidden a shameful situation for them. In all cases the forensic procedures continued their course. Aggression is one of the leading causes of head injuries. They occupy the first or second place according to studies [1]. In clinical terms, consciousness disorders and hemiparesis were the most common signs found in classical head injuries [2, 3]. In our 3 cases the neurological examination was normal because the middle third of the superior sagittal sinus injured had not bled enough (because the lesion was blocked by the nail still in place) and the associated parenchymal lesions were very minimal. These lesions can be fatal depending on the anatomical elements (large vessels...) crossed by the object penetrating the skull [4-6]. Death can occur either concomitantly with the penetration of the object or at the time of its removal by a sinus tear followed by uncontrolled cataclysmic bleeding. In our work precautions were taken not to increase the superior sagittal sinus lesion first by avoiding making an enlargement craniotomy around the nail and then pulling the nail in its axis with a measured force without any moment of back and forth or lateral inclination. Subsequently, bleeding from the superior sagittal sinus caused by nail removal was controlled by finger compression and stopped by placing hemostatic compress in the hole left by the nail. Apposition of epicranium reinforced the dura closure. Considering the position of the nails on the median line (superior sagittal sinus) at the local examination, the CT scan in axial section and sagittal and coronal reconstruction was essential to better analyze the trajectory of the nails before deciding on their ablation.. CT is very efficient for the diagnosis of lesions in brain injuries [7, 8]. However, the metal artifact can significantly reduce the performance of the scanner when the large metal penetrant object is still implanted in the skull at the time of performing the scanner. This was not the case in our work probably because of the small size of the nails and the nature of the metal. After this vital risk linked to the anatomical structures traversed by the penetrating object, two other risks are to be feared: infection (meningitis, sepsis, empyema, abscess...) [1, 9, 10] or epilepsy $[1,3]$. These risks call into question the systematic prescription of antibiotics and antiepileptic drugs in case of a penetrating head injuries. Thus, antibiotic prophylaxis was prescribed early by most authors [1,9]. Early surgery can significantly reduce the risk of infection [3]. The mortality of penetrating head injuries is heavy especially when the patient is admitted with a bad Glasgow score scale [11]. Conversely, a normal neurological examination at admission is a sign of a good prognosis as was the case in our work.

\section{Conclusion}

Posterior part of superior sagittal sinus injuries by carpenter's nails posed a medicolegal problem. They were usually done deliberately in a context of popular justice on a person recognized as criminal by a mob. This act was intended to kill by wounding and bleeding the superior 
sagittal sinus. The cases admitted to hospital before death were probably the luckiest. Their management consisted essentially of the removal of the nail (after a study of its trajectory to imaging) associated with good antibio prophylaxis. Bleeding of the superior sagittal sinus caused by nail removal was controlled by finger compression and stopped by burial of hemostatic compresses in the hole left by the nail. Apposition of epicranium reinforced the dura closure.

\section{References}

[1] Diop AA, Tine I, Hode L: les plaies crânio-encéphaliques: aspects épidémio-cliniques et thérapeutiques à Dakar (SENEGAL). African journal of neurological sciences. 2011; 30: $1-6$.

[2] KD Muballe, T Hardcastle, E Kiratu. Neurological findings in pediatric penetrating head injury at a university teaching hospital in Durban, South Africa: a 23-year retrospective study. Journal of Neurosurgery: Pediatrics. 2016; 18 (5): 550557.

[3] Bell RS, Mossop CM, Dirks MS, Stepens FL, Mulligan L, Ecker R and al. Early decompressive craniectomy for severe penetrating and closed head injury during wartime. Neurosurg Focus. 2010; 28 (5):1-6.

[4] Bodanapally UK, Saksobhavivat N, Shanmuganathan K, aarabi B, Roy AK. Arterial injuries after penetrating brain injury in civilians: risk factors on admission head computed tomography. J Neurosurg. 2015; 122:219-226.
[5] Arifin MZ, Gill AS, Faried A. Penetrating skull fracture by a wooden object: Management dilemmas and literature review. Asian J Neurosurg. 2012; 7 (3): 131-134.

[6] Kazim SF, Bhatti A, Godil SS. Craniocerebral injury by penetration of a T-shaped metallic spanner: A rare presentation. SurgNeurol Int. 2013; 4: 2.

[7] Daghfousa A, Bouzaïdi K, Abdelkefi M, Rebai S, Zoghlemi A, Mbarekc M, Rezgui L Marhoul. Apport de l'imagerie dans la prise en charge initiale des traumatismes balistiques. Journal de Radiologie Diagnostique et Interventionnelle. 2015; 96: 113-123.

[8] Bodanapally U K, ShanmUganathan K, BoScaK AR, Jaffray P M, Van der Byl G, Roy AK and al. Vascular complications of penetrating brain injury: comparison of helical CT angiography and conventional angiography. $\mathrm{J}$ Neurosurg. 2014; 121: 1275-1283.

[9] Quenuma J-M K, Quenuma B, Fanoua L, Akadiri R, Gnangnona A. Prise en charge des plaiescrânio-cérébrales à Cotonou (République du Bénin). Société de neurochirurgie de langue francaise / Neurochirurgie. 2013; 59: 225-263.

[10] Abdulbaki A, Al-Otaibi F, Almalki A, Alohaly N, Baeesa S. TransorbitalCraniocerebral Occult Penetrating Injury with Cerebral Abscess Complication. Case Rep Ophthalmol Med. 2012: 742-86.

[11] Geeraerts T Haïk W, Tremey B, Duranteau J, Vigue B, Troubles de la coagulation lors du traumatisme cranioencéphalique: physiopathologie et conséquences thérapeutiques. Annales Françaises d'Anesthésie et de Réanimation. 2010; 29: 177-181. 